\title{
Long-term Cost-effectiveness of Insulin Degludec Versus Insulin Glargine U100 in the UK: Evidence from the Basal-bolus Subgroup of the DEVOTE Trial (DEVOTE 16)
}

\author{
Richard F. Pollock ${ }^{1,6}$ (D) William J. Valentine ${ }^{1}$. Steven P. Marso ${ }^{2}$. Andreas Andersen ${ }^{3}$. Jens Gundgaard ${ }^{3}$. \\ Nino Hallén ${ }^{3}$. Deniz Tutkunkardas ${ }^{3}$. Elizabeth A. Magnuson ${ }^{4}$. John B. Buse ${ }^{5}$ on behalf of the DEVOTE study group
}

Published online: 2 July 2019

(c) The Author(s) 2019

\begin{abstract}
Objectives To evaluate the cost-effectiveness of insulin degludec (degludec) versus insulin glargine $100 \mathrm{units} / \mathrm{mL}$ (glargine U100) in basal-bolus regimens for patients with type 2 diabetes (T2D) at high cardiovascular (CV) risk based on the DEVOTE CV outcomes trial.

Methods A microsimulation model, informed by clinical outcomes from the subgroup of patients using basal-bolus insulin therapy in DEVOTE (NCT01959529) and by the UKPDS Outcomes Model 2 risk equations, was used to model direct costs (2018 GBP) and effectiveness outcomes [quality-adjusted life years (QALYs)] with degludec versus glargine U100 over a 40-year time horizon. The model captured the development of eight diabetes-related complications, death, severe hypoglycemia and insulin dosing. This analysis was conducted from the perspective of National Health Service (NHS) England.

Results Treatment with degludec versus glargine U100 in basal-bolus regimens was associated with improved clinical outcomes at a higher cost per patient [incremental cost effectiveness ratio (ICER): £14,956 GBP/QALY]. Degludec remained cost effective versus glargine U100 in all exploratory sensitivity analyses, with ICERs below the widely accepted willingnessto-pay threshold, although the result was most sensitive to assumptions regarding the persistence of treatment effects.

Conclusions Our long-term modeling analysis suggested that degludec was cost effective (from the perspective of NHS England) versus glargine U100 in basal-bolus regimens for patients with T2D at high CV risk. Our findings raise important questions regarding how to model the health economics of diabetes therapies.
\end{abstract}

Ossian Health Economics and Communications GmbH, Basel, Switzerland was Richard F. Pollock's affiliation at time of study.

Electronic supplementary material The online version of this article (https://doi.org/10.1007/s40258-019-00494-3) contains supplementary material, which is available to authorized users.

Richard F. Pollock

pollock@covalence-research.com

1 Ossian Health Economics and Communications GmbH, Basel, Switzerland

2 HCA Midwest Health Heart and Vascular Institute, Kansas City, MO, USA

3 Novo Nordisk A/S, Søborg, Denmark

4 Saint Luke's Mid America Heart Institute, Kansas City, MO, USA

5 Medicine/Endocrinology, University of North Carolina School of Medicine, Chapel Hill, NC, USA

6 Covalence Research Ltd, London, UK

\section{Key Points for Decision Makers}

The increasing number of completed cardiovascular (CV) outcomes trials provides new opportunities to model cost effectiveness based on long-term CV outcomes data.

We report the first such evaluation for insulin degludec (degludec) versus insulin glargine 100 units/mL (glargine U100) informed by data from a basal-bolus subgroup of the DEVOTE CV outcomes trial.

From the perspective of England's National Health Service, lifelong treatment with degludec was cost effective versus glargine U100 in basal-bolus regimens for patients with type 2 diabetes at high $\mathrm{CV}$ risk.

Our study raises important questions and makes proposals on how to model and analyze the cost-utility of diabetes therapies in the era of $\mathrm{CV}$ outcomes trials. 


\section{Introduction}

Type 2 diabetes (T2D) is a leading cause of morbidity and mortality worldwide [1]. The cost of treating diabetesrelated complications is substantial and often far exceeds the cost of blood glucose-lowering medications [2]. For T2D in the UK, only one-fifth of direct health costs relate to diabetes treatment and ongoing management, with the rest ( $80 \%$ of costs, estimated at over $£ 7$ billion GBP in 2011/12) spent treating complications of the disease [3]. The use of economic simulation modeling tools to support healthcare decision making is widespread and necessary [4]. This is particularly true for chronic, progressive diseases such as diabetes where the time-horizon of interest for decision making is patient lifetime, and hence well beyond the time and resource constraints of clinical trials [5].

Epidemiological evidence suggests that T2D is an independent risk factor for cardiovascular (CV) disease and microvascular complications [6]. Compared with the general population, patients with T2D are twice as likely to experience a CV event, with $60 \%$ of patients dying as a result of CV disease [7, 8]. Since the US Food and Drug Administration introduced guidance for industry in 2008 that requires an investigation of the CV safety of glucose-lowering medications, an increasing number of cardiovascular outcomes trials (CVOTs) have been conducted [9]. These large-scale trials provide a rigorous assessment of the $\mathrm{CV}$ safety of diabetes therapies in high-risk patient populations, and can provide a wealth of useful information and clinical data to inform health economic analyses [10]. This raises important questions on how to model the health economics of diabetes therapies.

Results were recently published from DEVOTE, a CVOT that compared the CV safety of insulin degludec (degludec) with that of insulin glargine 100 units/mL (glargine U100) in patients with T2D at high CV risk [11]. In DEVOTE, degludec was non-inferior to glargine U100 with respect to the incidence of CV events [hazard ratio: $0.91(0.78-1.06)_{95 \% \mathrm{CI}}$ ], whilst patients experienced significantly fewer episodes of severe hypoglycemia [rate ratio: $0.60(0.48-0.76)_{95 \% \mathrm{CI}}$, at similar levels of glycemic control with degludec versus glargine U100 [11]. Prior to DEVOTE, evaluations of the cost effectiveness of degludec versus glargine U100 captured the effects of hypoglycemia rates and insulin dosing over short-term (1-year) time horizons, informed by phase 3 clinical trial data [12-18]. Such analyses were restricted to short time horizons because the treat-to-target design of trials required by regulatory bodies renders longer-term modeling based on $\mathrm{HbA}_{1 \mathrm{c}}$ outcomes non-informative. A similar approach has been taken based on data from DEVOTE, which also had a treat-to-target design, but this model captured $\mathrm{CV}$ outcomes in addition to severe hypoglycemia rates and insulin dosing over a 2-year time horizon [19]. DEVOTE provides the opportunity to source clinical data for degludec and glargine U100 from a single, high-quality source to inform longer-term modeling based on CV outcomes.

Patients with T2D receiving basal-bolus therapy tend to have advanced disease, and are thus at an increased risk of poor clinical outcomes and associated healthcare costs [20, 21]. The aim of the present analysis was to develop a health economic decision model to evaluate the longterm cost effectiveness of degludec versus glargine U100 in basal-bolus regimens from the perspective of National Health Service (NHS) England.

\section{Methods}

\subsection{DEVOTE Trial Design}

The design and primary results of DEVOTE have been previously published $[11,22]$. In brief, DEVOTE was a double-blind, randomized, treat-to-target, active comparatorcontrolled CVOT conducted at 438 sites in 20 countries. Patients with T2D at high CV risk were randomized 1:1 to receive degludec (100 units/mL) or glargine U100, both in addition to standard care. Patients considered at high $\mathrm{CV}$ risk and eligible for the trial were aged $\geq 50$ years of age with one or more coexisting $\mathrm{CV}$ or renal condition, or aged $\geq 60$ years of age with one or more $\mathrm{CV}$ risk factors. The primary composite outcome in DEVOTE was the first occurrence of death from $\mathrm{CV}$ causes, non-fatal myocardial infarction (MI) or non-fatal stroke [collectively termed a major adverse cardiovascular event (MACE)]. Secondary endpoints included time from randomization to death from any cause, and the incidence and rates of severe hypoglycemia, which was defined according to the American Diabetes Association definition as requiring the assistance of another person to actively administer carbohydrate or glucagon or to take other corrective actions [23]. Data on non-severe hypoglycemia were not collected. In DEVOTE, median exposure time was 1.83 years and median observation time was 1.99 years [11]. The basal-bolus subgroup of DEVOTE ( $n=3515)$ was defined as using bolus insulin (in a basal-bolus, premix or bolus-only regimen) at baseline before switching basal insulin to (or adding) degludec or glargine U100 in a basal-bolus regimen [11]. Clinical outcomes for the DEVOTE basal-bolus subgroup have been previously published [19].

\subsection{Model Structure}

A Monte Carlo microsimulation model developed in Java 8 (Oracle Corporation, Redwood Shores, CA) was used to 
model CV death, non-fatal MI, non-fatal stroke and death from other causes (i.e. any cause except for CV disease) over a 2-year period based on clinical outcomes from the DEVOTE basal-bolus subgroup. UKPDS Outcomes Model 2 (UKPDS OM2) risk equations [24] were used to model other diabetes-related complications over the first 2 years, as well as first MACE, death from other causes and other diabetesrelated complications over a subsequent 38 -year period (for a total time horizon of 40 years). Severe hypoglycemic events were modeled based on DEVOTE over the entire 40-year time horizon. The model was structured in line with the UKPDS Outcomes Model, which is a "probabilistic discretetime illness-death model with annual cycles" [25]. Model coefficients and equations were internally validated against the values reported in the UKPDS OM2 using the Lipids in Diabetes Study population (refer to Online resource 1) [24, 26]. $\mathrm{HbA}_{1 \mathrm{c}}$ and systolic blood pressure progressions were based on the panel regression equations from the UKPDS Outcomes Model 1 [25], with all other risk factors held constant over time (Online resource 2). The model captured the development of eight diabetes-related complications (congestive heart failure, ischemic heart disease, renal failure, ulcer and blindness; in addition to first and second events for non-fatal MI, non-fatal stroke and amputation), death from other causes, severe hypoglycemia, insulin dosing, quality-adjusted life expectancy (QALE) and direct medical costs with degludec versus glargine U100 (refer to Online resource 3 for flowchart of model structure).

The base case analysis was run over a 40-year time horizon and included assumptions regarding the persistence of treatment effects (degludec vs glargine U100) observed in the DEVOTE basal-bolus subgroup. Differences in the incidence of individual components of first MACE, and death from other causes were modeled using the glargine U100 rates and degludec hazard ratios from DEVOTE in years 1 and 2 (corresponding to the DEVOTE trial period); all subsequent differences in incidence were dependent exclusively on differences in risk arising from the simulated patient-level history of events occurring in years 1 and 2. Differences in insulin dosing and the incidence of severe hypoglycemia were maintained over the full 40-year analysis time horizon.

A patient-level model was selected (as opposed to a cohort level model) to allow flexibility in modeling multiple simultaneous disease history states. The present Monte Carlo microsimulation model addressed two forms of uncertainty: 'first order' or Monte Carlo uncertainty was minimized by using large numbers of Monte Carlo replications until mean outcomes were stable, while 'second order' or parameter uncertainly was captured by sampling from normal and lognormal distributions around DEVOTE trial outcomes and through the use of UKPDS OM2 risk equations (estimated model coefficients and confidence intervals derived from bootstrapped parameter distributions) [24].

\subsection{Model Inputs: Clinical Data}

For the glargine U100 arm, within-trial event rates for the DEVOTE basal-bolus subgroup were used to model rates of severe hypoglycemia, death from CV causes, non-fatal MI and non-fatal stroke (Table 1). Time to first non-fatal MI, first non-fatal stroke, and death from cardiovascular causes were analyzed separately using a Cox proportional-hazards regression model to provide a hazard ratio (degludec/glargine U100) for each individual component of the composite MACE endpoint. The number of severe hypoglycemic episodes was analyzed using a negative binomial regression model with a log-link function and $\log$ (duration of observation time) as offset. Death from other causes (i.e. any cause except for first MACE) was analyzed using a Cox proportional-hazards regression model. Regression analyses (described above) were conducted as per the prespecified primary DEVOTE analyses without additional covariates [11]. The resulting rate ratios and hazard ratios were applied to the glargine U100 event rates, sampling both from normal distributions around the glargine U100 event rates and lognormal distributions around the rate and hazard ratios to derive event rates in the degludec arm (Table 1).

For the glargine U100 arm, mean basal and bolus insulin doses in years 1 and 2 were derived from the DEVOTE data, and were taken as the arithmetic mean of the doses at baseline and 12 months (for year 1) and at 12 and 24 months (for year 2) to provide an estimate of area under the curve. End-of-trial glargine U100 doses were used to model the doses in year 3 onwards, with basal and bolus dose differences maintained over the full time horizon. Estimated dose ratios from regression analyses (described below) were applied to the glargine U100 values to derive dose inputs for the degludec arm (Table 1). Insulin dose was analyzed with a mixed model for repeated measures within patients using an unstructured residual covariance matrix among visits. Visit interactions with age, dose at baseline, body mass index, alternative titration target (yes/no) and treatment were included in the model as fixed effect covariates. The model did not capture differences in $\mathrm{HbA}_{1 \mathrm{c}}$ as the treat-to-target design of DEVOTE resulted in equivalent changes in $\mathrm{HbA}_{1 \mathrm{c}}$ from baseline to 24 months in the DEVOTE basal-bolus subgroup [19].

\subsection{Model Inputs: Simulation Cohort}

A simulated cohort of $1,000,000$ patients in each treatment arm was generated based upon the patient demographics, baseline risk factors, and complication histories from the basal-bolus subgroup of DEVOTE (available in Online resource 4). 
Table 1 Clinical model inputs

$\begin{array}{llllll}\begin{array}{l}\text { Degludec/glar- } \\ \text { gine U100 ratio }\end{array} & \text { Ratio type } & \text { SE } & 95 \% \text { CI } & \text { Glargine U100 arm } & \begin{array}{l}\text { Estimated } \\ \text { degludec } \\ \text { arm }^{\mathrm{a}}\end{array}\end{array}$

\begin{tabular}{|c|c|c|c|c|c|c|}
\hline Complications & & & & & Annual rates & \\
\hline First $\mathrm{MACE}^{\mathrm{b}, \mathrm{c}}$ & 0.805 & Hazard ratio & 0.10 & {$[0.658-0.984]$} & 0.0607 & 0.0489 \\
\hline Non-fatal MI & 0.679 & Hazard ratio & 0.15 & {$[0.504-0.914]$} & 0.0292 & 0.0198 \\
\hline Non-fatal stroke & 0.737 & Hazard ratio & 0.22 & {$[0.476-1.142]$} & 0.0124 & 0.0091 \\
\hline $\mathrm{CV}$ death & 0.920 & Hazard ratio & 0.15 & [0.676-1.253] & 0.0191 & 0.0176 \\
\hline Severe hypoglycemia ${ }^{c}$ & 0.630 & Rate ratio & 0.152 & [0.468-0.849] & 0.0850 & 0.0536 \\
\hline Death from other causes ${ }^{\mathrm{c}, \mathrm{d}}$ & 0.766 & Hazard ratio & 0.192 & {$[0.525-1.116]$} & 0.0179 & 0.0137 \\
\hline Basal insulin dose $e^{\mathrm{c}}$ & & & & & Units per day & \\
\hline Baseline & N/A & & & & 49.0 & 49.0 \\
\hline 12 months & 1.031 & Ratio of mean doses & 0.016 & [1.000-1.064] & 65.1 & 67.1 \\
\hline 24 months & 1.061 & Ratio of mean doses & 0.022 & [1.016-1.108] & 70.4 & 74.7 \\
\hline Bolus insulin dose & & & & & Units per day & \\
\hline Baseline & N/A & & & & 39.4 & 39.4 \\
\hline 12 months & 0.954 & Ratio of mean doses & 0.024 & {$[0.910-1.000]$} & 59.5 & 56.8 \\
\hline 24 months & 0.955 & Ratio of mean doses & 0.036 & [0.891-1.025] & 69.7 & 66.6 \\
\hline
\end{tabular}

$C I$ confidence interval, $C V$ cardiovascular, glargine $U 100$ glargine 100 units/mL, MACE major adverse cardiovascular event, $M I$ myocardial infarction, N/A not applicable, $S E$ standard error

${ }^{a}$ Due to the stochastic nature of the model, estimated values for the degludec arm varied in each simulation

${ }^{b}$ Composite first MACE primary endpoint, however only the individual components were used in the model

${ }^{c}$ Previously reported in Pollock et al. [19]

${ }^{\mathrm{d}}$ Includes any deaths that are not from first MACE

\subsection{Model Inputs: Costs and Perspective}

This analysis was conducted from the perspective of NHS England. Treatment unit costs were based on 2018 UK list prices (Table 2). In both treatment arms, it was assumed that a new needle and self-measured blood glucose test strip were used per injection, and that patients administered four injections per day. Diabetes-related complication and adverse event costs were extracted from the literature and inflated to 2017 GBP prices (the most recent available year) using the hospital and community health services index from the Personal Social Services Research Unit [27] (Table 2).

\subsection{Model Inputs: Utility, Time Horizon and Discounting}

Diabetes-related health state utility and disutility values were extracted from published sources (Table 2). The simulation was run over a 40-year time horizon, sufficient to capture lifetime costs and effectiveness outcomes in the simulated patient cohort (mean age at baseline of 65.1 years). All future costs and clinical benefits were discounted at an annual rate of 3.5\% in accordance with the National Institute for Health and Care Excellence (NICE) recommendations [28].

\subsection{Sensitivity Analyses}

Exploratory simulations were run varying the discount rate, time horizon (2 years), shape of the $\mathrm{HbA}_{1 \mathrm{c}}$ progression curve, and with alternative costs or disutilities extracted from the literature. Additional sensitivity analyses explored the influence of varying assumptions regarding the following clinical parameters: abolishing individual effects of treatment on $\mathrm{CV}$ death, MI, stroke or severe hypoglycemia; extending effects of treatment on MACE by 1-3 years beyond the DEVOTE trial period; applying MACE hazard ratios to UKPDS projections of MACE in years 3-40; removing effects of insulin dose differences; and removing all differences (switch to glargine U100) after 2-10 years.

A probabilistic sensitivity analysis based on Monte Carlo simulation with non-parametric bootstrapping was used to derive estimates of uncertainty around base case outcomes based on 1000 iterations of N/50 (i.e. 20,000 where $N=1,000,000)$ patients in each simulation arm. All 'baseline' values (i.e. those in the glargine U100 arm) and disutility values were sampled from normal distributions, while all hazard rate and dose ratios were sampled from lognormal distributions. One thousand estimates of incremental costs and incremental effectiveness in terms of QALYs were plotted on a cost-effectiveness scatterplot and used to plot a costeffectiveness acceptability curve (CEAC). The incremental 
Table 2 Unit costs and utility data

\begin{tabular}{|c|c|c|c|c|c|}
\hline Parameter & Value & SE & Unit & Source & $\begin{array}{l}\text { HRQoL preference } \\
\text { elicitation method }^{a}\end{array}$ \\
\hline \multicolumn{6}{|l|}{ Treatment costs (unit price) } \\
\hline Glargine $\mathrm{U} 100^{\mathrm{b}}$ & 0.0252 & 0 & GBP & MIMS [31] & \\
\hline Degludec $^{c}$ & 0.0311 & 0 & GBP & MIMS [31] & \\
\hline IAsp $^{\mathrm{d}}$ & 0.0204 & 0 & GBP & MIMS [31] & \\
\hline Needle $^{e}$ & 0.0969 & 0 & GBP & MIMS [31] & \\
\hline $\mathrm{SMBG}^{\mathrm{f}}$ & 0.3507 & 0 & GBP & MIMS [31] & \\
\hline \multicolumn{6}{|l|}{ Complication costs ${ }^{\mathrm{g}}$} \\
\hline MI, year 1 & 7857 & 1105 & GBP & Alva et al. [32] & \\
\hline MI, year 2+ & 1953 & 164 & GBP & Alva et al. [32] & \\
\hline Stroke, year 1 & 8449 & 1753 & GBP & Alva et al. [32] & \\
\hline Stroke, year $2+$ & 2013 & 243 & GBP & Alva et al. [32] & \\
\hline Amputation, year 1 & 13,103 & 1924 & GBP & Alva et al. [32] & \\
\hline Amputation, year 2+ & 3642 & 514 & GBP & Alva et al. [32] & \\
\hline Blindness, year 1 & 3365 & 611 & GBP & Alva et al. [32] & \\
\hline Blindness, year 2+ & 1274 & 103 & GBP & Alva et al. [32] & \\
\hline Heart failure, year 1 & 4462 & 880 & GBP & Alva et al. [32] & \\
\hline Heart failure, year $2+$ & 2617 & 361 & GBP & Alva et al. [32] & \\
\hline Ischemic heart disease, year 1 & 11,376 & 1545 & GBP & Alva et al. [32] & \\
\hline Ischemic heart disease, year $2+$ & 2000 & 159 & GBP & Alva et al. [32] & \\
\hline Renal failure, year 1 & 18,073 & 0 & GBP & NHS tariff value $[33,34]$ & \\
\hline Renal Failure, year 2+ & 18,073 & 0 & GBP & NHS tariff value $[33,34]$ & \\
\hline Ulcer, year $1^{\mathrm{h}}$ & 2050 & 0 & GBP & Ghatnekar et al. [35] & \\
\hline Ulcer, year $2 t^{\mathrm{h}}$ & 276 & 0 & GBP & Ghatnekar et al. [35] & \\
\hline Severe hypoglycemia & 427 & 0 & GBP & Hammer et al. [36] & \\
\hline \multicolumn{6}{|l|}{ Utilities $^{\mathrm{i}}$} \\
\hline Base & 0.785 & 0 & $\mathrm{U}$ & Clarke et al. [37] & $E Q-5 D^{j}$ \\
\hline MI & -0.055 & 0.006 & DisU & Clarke et al. [37] & $E Q-5 D^{j}$ \\
\hline Stroke & -0.164 & 0.030 & DisU & Clarke et al. [37] & EQ-5D \\
\hline Amputation & -0.28 & 0.056 & DisU & Clarke et al. [37] & $E Q-5 D^{j}$ \\
\hline Blindness & -0.074 & 0.033 & DisU & Clarke et al. [37] & EQ-5D \\
\hline Heart failure & -0.108 & 0.031 & DisU & Clarke et al. [37] & EQ-5D \\
\hline Ischemic heart disease & -0.09 & 0.018 & DisU & Clarke et al. [37] & $E Q-5 D^{j}$ \\
\hline Renal failure & -0.164 & 0.015 & DisU & Wasserfallen et al. [38] & $E Q-5 D^{j}$ \\
\hline Ulcer & -0.17 & 0.019 & DisU & Bagust and Beale [39] & EQ-5D \\
\hline Severe hypoglycemia & -0.057 & 0.002 & DisU & Evans et al. [40] & $\mathrm{TTO}^{\mathrm{k}}$ \\
\hline
\end{tabular}

Dis $U$ disutility, EQ-5D EuroQol-5D, GBP pounds sterling, Glargine U100 insulin glargine 100 units/mL, $H R Q o L$ health-related quality of life, $I A s p$ insulin aspart, $M I$ myocardial infarction, $M I M S$ monthly index of medical specialties, $S E$ standard error, $S M B G$ self-measured blood glucose, TTO time trade-off, $U$ utility, $U K$ United Kingdom

${ }^{\mathrm{a}}$ Only applicable to utility values

${ }^{b}$ Lantus $^{\circledR}$ (in Solostar ${ }^{\circledR}$ pen): $£ 37.77$ GBP for 1500 units

${ }^{\mathrm{c}}$ Insulin degludec (in FlexTouch ${ }^{\circledR}$ pen): $£ 46.60$ GBP for 1500 units

${ }^{\mathrm{d}}$ Insulin aspart (in FlexPen ${ }^{\circledR}$ ): $£ 30.60 \mathrm{GBP}$ for 1500 units

${ }^{\mathrm{e}} \mathrm{BD}$ MicroFine ${ }^{\circledR} 5 \mathrm{~mm}$ : $99.69 \mathrm{GBP}$ per 100 needles

${ }^{\text {f }}$ SMBG test costs based on the use of one Accu-Chek ${ }^{\circledR}$ Aviva test strip (£16.09 GBP for 50 units) and one Accu-Chek ${ }^{\circledR}$ FastClix lancet (£5.90 GBP for 204 units) per test

${ }^{g}$ Inflation-adjusted to 2017 prices using the hospital and community health services index from the Personal Social Services Research Unit [27]. SEs cover hospital costs only as SEs for total costs (hospital costs and non-inpatient healthcare costs) were not available. For renal failure, ulcer and severe hypo no SEs were available

${ }^{\mathrm{h}}$ Currency converted based on a Euro/GBP exchange rate of 0.6239 correct as of 01 January 2000 (www.oanda.com)

${ }^{i}$ SEs calculated using this equation (when required information available). SE=(lower $95 \%$ confidence limit-upper $95 \%$ confidence limit)/ $(2 \times 1.96)$; assuming the sampling is normally distributed

${ }^{\mathrm{j}}$ Three level EQ-5D based on TTO elicited by the general UK population

${ }^{\mathrm{k}}$ TTO elicited by the general population from five countries (including the UK) 
cost-effectiveness ratio (ICER) for degludec versus glargine U100 was compared to the widely accepted UK willingnessto-pay threshold range of $£ 20,000-£ 30,000$ GBP per QALY gained [29].

\section{Results}

\subsection{Base Case Analysis}

Treatment with degludec was associated with mean QALE of 6.8980 years at a mean cost of $£ 47,311$ GBP per patient, compared with 6.7825 years at a mean total cost of $£ 45,582$ GBP per patient with glargine U100 (Table 3). Bootstrapped 95\% CIs and credible intervals around costs and QALYs are presented in Online resource 5. Improved clinical outcomes with degludec were driven primarily by a lower incidence of severe hypoglycemia, CV death and death from other causes, and, to a smaller extent, by reduced rates of non-fatal stroke and non-fatal MI. Higher acquisition costs with degludec were partially offset by lower costs of non-fatal MI, severe hypoglycemia and non-fatal stroke. This yielded an ICER of $£ 14,956$ GBP per QALY gained with degludec versus glargine U100 (Table 3). The cumulative incidences of diabetes-related complications for each simulation arm over the 40-year time horizon are presented in Online resource 6.

\subsection{Sensitivity Analyses}

Degludec remained cost effective versus glargine U100 in all sensitivity analyses, with ICERs below the widely accepted NICE willingness-to-pay lower threshold value of $£ 20,000$ GBP per QALY (Table 4). Varying model assumptions, quality-of-life disutilities, and complication cost estimates did not have a large impact on the ICER (which remained within $£ 2000$ GBP per QALY of the base case ICER), with the exception of a 2-year time horizon (as opposed to a 40-year time horizon), which saw the ICER decrease to $£ 7828$ GBP per QALY gained (Table 4).

Most variations in treatment effects had a large influence on the resulting ICER, except for removing the interarm differences in $\mathrm{CV}$ death or bolus insulin dose. The ICER increased from the base case $(£ 14,956$ GBP per QALY) to over $£ 19,000$ GBP per QALY when the effect of treatment on non-fatal MI, non-fatal stroke or severe hypoglycemia was removed, highlighting the importance of these clinical parameters to the overall result. In all sensitivity analyses where the duration of treatment effects was increased beyond the DEVOTE trial period, the ICER was lower than the base case, that is, degludec was more cost effective relative to glargine U100 (Table 4).
The most substantial change from the base case ICER was observed when the basal insulin price difference and all treatment effects were abolished after 2 years (i.e. the degludec arm switched treatment to glargine U100 after the DEVOTE in-trial period) in which the ICER decreased to $£ 2292$ GBP per QALY, followed by analyses in which the basal insulin price difference and all treatment effects were abolished after 3, 4 or 5 years. Extending the duration of treatment effects for MACE events reduced the ICER with each additional year of extension, declining to $£ 8973$ GBP per QALY when applied in years 1-5 (a 3 -year extension from the base case analysis). Similarly, incremental reductions in the ICER were observed with each additional year in which the MACE hazard ratios (observed in the DEVOTE basal-bolus subgroup) were applied to UKPDS projections of MACE events (used to model event rates in years 3-40 in the base case analysis) (Table 4).

Results of the probabilistic sensitivity analysis indicated that degludec was associated with QALY gains in this group of patients at an increased cost versus glargine U100, with the majority of bootstrap samples falling in the Northeast quadrant of the cost-effectiveness scatterplot (Fig. 1a). The CEAC showed that the likelihood of degludec being cost effective was $72.7 \%$ and $88.0 \%$ at willingness-to-pay thresholds of $£ 20,000$ and $£ 30,000$ GBP per QALY, respectively (Fig. 1b).

\section{Discussion}

Our long-term modeling analysis demonstrated that, from the perspective of NHS England, degludec provides good value for money compared with glargine U100 as part of basal-bolus insulin therapy in patients with advanced T2D at high CV risk. Lifelong treatment with degludec remained cost effective versus glargine U100 in all sensitivity analyses, yielding ICERs below the NICE willingness-to-pay lower threshold value of $£ 20,000$ GBP per QALY. Despite the robustness of the overall result supporting the cost effectiveness of degludec, sensitivity analyses revealed that the ICER was sensitive to variations in a number of model parameters (with ICER estimates ranging from $£ 2292$ to $£ 19,848$ GBP per QALY).

The ICER was particularly sensitive to assumptions regarding the duration of treatment effects, most notably the removal of all differences after 2 years (i.e. the DEVOTE in-trial period). This highlights the importance of assumptions of this type in long-term health-economic analyses for the treatment of chronic and progressive diseases such as diabetes. Our base case analysis was highly conservative, with the effect of treatment on first MACE presumed not to extend beyond the DEVOTE trial period of 2 years. With 
Table 3 Results of the base case analysis

\begin{tabular}{|c|c|c|c|}
\hline & Degludec & Glargine U100 & $\begin{array}{l}\text { Difference (deglu- } \\
\text { dec-glargine } \\
\text { U100) }\end{array}$ \\
\hline \multicolumn{4}{|l|}{ Costs $(G B P)$} \\
\hline Total costs & 47,311 & 45,582 & 1729 \\
\hline Treatment and SMBG costs & 20,214 & 18,229 & 1986 \\
\hline \multicolumn{4}{|l|}{ Costs of complications } \\
\hline MI & 9003 & 9198 & -196 \\
\hline Stroke & 4254 & 4336 & -81 \\
\hline Hypoglycemia & 226 & 355 & -129 \\
\hline Heart failure & 5262 & 5189 & 74 \\
\hline Ischemic heart disease & 4553 & 4511 & 42 \\
\hline Amputation & 2670 & 2653 & 18 \\
\hline Renal failure & 390 & 386 & 4 \\
\hline Ulcer & 316 & 312 & 3 \\
\hline Blindness & 421 & 414 & 7 \\
\hline \multicolumn{4}{|l|}{ Effects } \\
\hline \multicolumn{4}{|l|}{$Q A L Y s$} \\
\hline Total QALYs & 6.8980 & 6.7825 & 0.1156 \\
\hline Baseline & 8.1018 & 8.0020 & 0.0998 \\
\hline MI & -0.2213 & -0.2241 & 0.0028 \\
\hline Stroke & -0.2863 & -0.2897 & 0.0034 \\
\hline Hypoglycemia & -0.0299 & -0.0469 & 0.0170 \\
\hline Heart failure & -0.2112 & -0.2083 & -0.0030 \\
\hline Ischemic heart disease & -0.1516 & -0.1502 & -0.0014 \\
\hline Amputation & -0.1143 & -0.1136 & -0.0007 \\
\hline Renal failure & -0.0035 & -0.0035 & -0.0000 \\
\hline Ulcer & -0.1652 & -0.1632 & -0.0020 \\
\hline Blindness & -0.0205 & -0.0201 & -0.0004 \\
\hline \multicolumn{4}{|c|}{ Incremental cost-effectiveness ratio } \\
\hline ICER (Cost/QALY) & & & 14,956 \\
\hline
\end{tabular}

Costs and QALYs are discounted by $3.5 \%$. Baseline QALYs capture life expectancy

GBP pounds sterling, Glargine U100 insulin glargine 100 units/mL, ICER incremental cost-effectiveness ratio, $M I$ myocardial infarction, $Q A L Y$ quality adjusted life-year, $S M B G$ self-measured blood glucose this treatment effect extended by just one additional year, the ICER for degludec versus glargine U100 decreases by $£ 3221$ GBP per QALY, with further reductions with each additional year of extension. With the assumption of lifetime reductions in MACE incidence with degludec versus glargine U100, there would be a gain of 0.6832 QALYs and a concomitant reduction in the ICER, but only marginally over the assumption of a 5-year MACE advantage (Table 4). This is likely due to the survivors' paradox whereby patients continue to incur costs while they remain alive. This emphasizes the importance of establishing the duration of $\mathrm{CV}$ benefits to validate model assumptions and improve the accuracy of long-term health-economic predictions for diabetes therapies.

Results from a previous short-term (2-year time horizon) cost-utility analysis informed by data from the DEVOTE basal-bolus subgroup reported that degludec was associated with improved clinical outcomes at cost neutrality (no difference in costs from an NHS England perspective) versus glargine U100 in patients with T2D at high CV risk [19]. However, it should be noted that prices and unit costs have since changed rendering direct comparisons problematic. Similarly, a short-term (1-year) cost-effectiveness analysis for the treatment of T2D in basal-bolus regimens in the UK reported that degludec is a cost-effective treatment versus glargine U100, also reporting an ICER below the NICE willingness-to-pay lower threshold value despite only evaluating the effects of hypoglycemia and insulin dosing [15].

According to NICE guidance on the methods for health technology appraisal, the time horizon for evaluating cost effectiveness should be sufficiently long to reflect all important differences in costs or outcomes between comparators [28]. 
Table 4 Sensitivity analyses

\begin{tabular}{|c|c|c|c|c|c|c|c|c|}
\hline \multirow[t]{2}{*}{ Variation } & \multirow{2}{*}{$\begin{array}{l}\text { Parameter(s) in base } \\
\text { case model }\end{array}$} & \multicolumn{3}{|c|}{ Costs (GBP) } & \multicolumn{3}{|c|}{ QALE (QALYs) } & \multirow{2}{*}{$\begin{array}{l}\mathrm{ICER}^{\mathrm{b}} \\
(\mathrm{GBP} / \\
\mathrm{QALY}\end{array}$} \\
\hline & & Degludec & Glargine U100 & Incremental $^{\mathrm{a}}$ & Degludec & Glargine U100 & Incremental $^{\mathrm{a}}$ & \\
\hline Base case & N/A & 47,311 & 45,582 & +1729 & 6.8980 & 6.7825 & +0.1156 & 14,956 \\
\hline \multicolumn{9}{|l|}{ Model assumptions } \\
\hline No discounting & \multirow[t]{2}{*}{ Discounting $(3.5 \%)$} & 63,001 & 60,563 & +2438 & 9.1766 & 9.0144 & +0.1622 & 15,028 \\
\hline Discounting (5\%) & & 42,644 & 41,122 & +1522 & 6.2232 & 6.1212 & +0.1020 & 14,923 \\
\hline Flat $\mathrm{HbA}_{1 \mathrm{c}}$ curve & $\begin{array}{l}\text { Progressions based } \\
\text { on UKPDS OM1 } \\
\text { equations }\end{array}$ & 47,338 & 45,622 & +1716 & 7.0080 & 6.9025 & +0.1055 & 16,264 \\
\hline \multicolumn{9}{|c|}{ Treatment effects_-individual MACE components } \\
\hline $\begin{array}{l}\text { No difference in } \mathrm{CV} \\
\text { death }\end{array}$ & \multirow{3}{*}{$\begin{array}{l}\text { Applied years } 1-2 ; \\
\text { based on UKPDS } \\
\text { OM2 projections } \\
\text { years } 3+\end{array}$} & 47,193 & 45,582 & +1611 & 6.8779 & 6.7825 & +0.0954 & 16,884 \\
\hline $\begin{array}{l}\text { No difference in } \\
\text { non-fatal MI }\end{array}$ & & 47,579 & 45,582 & +1998 & 6.8831 & 6.7825 & +0.1006 & 19,848 \\
\hline $\begin{array}{l}\text { No difference in } \\
\text { non-fatal stroke }\end{array}$ & & 47,390 & 45,582 & +1808 & 6.8771 & 6.7825 & +0.0946 & 19,113 \\
\hline \multicolumn{9}{|c|}{ Treatment effects—severe hypoglycemia } \\
\hline No difference & Applied years $1-40$ & 47,448 & 45,582 & +1866 & 6.8771 & 6.7825 & +0.0946 & 19,718 \\
\hline \multicolumn{9}{|c|}{ Treatment effects-MACE events ${ }^{\mathrm{c}, \mathrm{d}}$} \\
\hline Extended to year 3 & \multirow[t]{4}{*}{ Applied years $1-2$} & 48,352 & 46,584 & +1769 & 6.9053 & 6.7546 & +0.1507 & 11,735 \\
\hline Extended to year 4 & & 49,507 & 47,630 & +1877 & 6.9316 & 6.7473 & +0.1843 & 10,180 \\
\hline Extended to year 5 & & 50,669 & 48,747 & +1922 & 6.9631 & 6.7488 & +0.2142 & 8973 \\
\hline \multicolumn{8}{|l|}{$\begin{array}{l}\text { Treatment effects- } \\
\text { MACE events }{ }^{\mathrm{c}, \mathrm{e}}\end{array}$} & \\
\hline $\begin{array}{l}\text { HRs applied to } \\
\text { UKPDS projec- } \\
\text { tions year } 3\end{array}$ & \multirow[t]{4}{*}{$\begin{array}{l}\text { Based on UKPDS } \\
\text { OM2 projections } \\
\text { years } 3+\end{array}$} & 47,563 & 45,582 & +1982 & 6.9399 & 6.7825 & +0.1575 & 12,583 \\
\hline $\begin{array}{l}\text { HRs applied to } \\
\text { UKPDS projec- } \\
\text { tions years 3-4 }\end{array}$ & & 47,882 & 45,582 & +2301 & 6.9807 & 6.7825 & +0.1982 & 11,607 \\
\hline $\begin{array}{l}\text { HRs applied to } \\
\text { UKPDS projec- } \\
\text { tions years 3-5 }\end{array}$ & & 48,149 & 45,582 & +2567 & 7.0171 & 6.7825 & +0.2347 & 10,940 \\
\hline $\begin{array}{l}\text { HRs applied to } \\
\text { UKPDS projec- } \\
\text { tions years 3-40 }\end{array}$ & & 51,174 & 45,582 & +5593 & 7.4656 & 6.7825 & +0.6832 & 8186 \\
\hline \multicolumn{9}{|c|}{ No differences (switch to glargine U100) } \\
\hline After 2 years & \multirow{6}{*}{$\begin{array}{l}\text { Treatment with } \\
\text { degludec or glargine } \\
\text { U100 in years } 1-40\end{array}$} & 45,747 & 45,582 & +166 & 6.8547 & 6.7825 & +0.0723 & 2292 \\
\hline After 3 years & & 46,063 & 45,582 & +481 & 6.8810 & 6.7825 & +0.0985 & 4881 \\
\hline After 4 years & & 46,239 & 45,582 & +657 & 6.8847 & 6.7825 & +0.1022 & 6426 \\
\hline After 5 years & & 46,372 & 45,582 & +790 & 6.8875 & 6.7825 & +0.1050 & 7524 \\
\hline After 10 years & & 46,797 & 45,582 & +1215 & 6.8940 & 6.7825 & +0.1115 & 10,893 \\
\hline \multicolumn{8}{|l|}{$\begin{array}{l}\text { Treatment effects- } \\
\text { insulin dose }\end{array}$} & \\
\hline $\begin{array}{l}\text { No bolus dose dif- } \\
\text { ference }\end{array}$ & Applied years 1-40 & 47,537 & 45,582 & +1955 & 6.8980 & 6.7825 & +0.1156 & 16,916 \\
\hline $\begin{array}{l}\text { No basal or bolus } \\
\text { dose difference }\end{array}$ & & 47,084 & 45,582 & +1503 & 6.8980 & 6.7825 & +0.1156 & 12,998 \\
\hline \multicolumn{9}{|l|}{ Input parameters ${ }^{\mathrm{f}}$} \\
\hline 2-year time horizon & 40-year time horizon & 8229 & 8157 & +72 & 1.3035 & 1.2944 & +0.0092 & 7828 \\
\hline $\begin{array}{l}\text { Severe hypoglyce- } \\
\text { mia cost-Waugh } \\
\text { et al. [41] }\end{array}$ & Hammer et al. [36] & 47,137 & 45,310 & +1827 & 6.8980 & 6.7825 & +0.1156 & 15,809 \\
\hline
\end{tabular}


Table 4 (continued)

\begin{tabular}{|c|c|c|c|c|c|c|c|c|}
\hline \multirow[t]{2}{*}{ Variation } & \multirow{2}{*}{$\begin{array}{l}\text { Parameter(s) in base } \\
\text { case model }\end{array}$} & \multicolumn{3}{|c|}{ Costs (GBP) } & \multicolumn{3}{|c|}{ QALE (QALYs) } & \multirow{2}{*}{$\begin{array}{l}\text { ICER }^{\mathrm{b}} \\
(\mathrm{GBP} / \\
\text { QALY) }\end{array}$} \\
\hline & & Degludec & Glargine U100 & Incremental $^{\mathrm{a}}$ & Degludec & Glargine U100 & Incremental $^{\mathrm{a}}$ & \\
\hline $\begin{array}{l}\text { Severe hypoglyce- } \\
\text { mia disutility }{ }^{\mathrm{g}}- \\
\text { Currie et al. [42] }\end{array}$ & Evans et al. [40] & 47,311 & 45,582 & +1729 & 6.9217 & 6.8196 & +0.1021 & 16,927 \\
\hline $\begin{array}{l}\text { Non-fatal MI and } \\
\text { non-fatal stroke } \\
\text { costs-Hunt et al. } \\
\text { [43] }\end{array}$ & Alva et al. [32] & 43,057 & 41,267 & +1791 & 6.8980 & 6.7825 & +0.1156 & 15,490 \\
\hline \multicolumn{9}{|l|}{ Alternative disutilities } \\
\hline Sullivan et al. [44] & Clarke et al. [37] & 47,311 & 45,582 & +1729 & 7.5102 & 7.4002 & +0.1100 & 15,717 \\
\hline Palmer et al. [45] & & 47,311 & 45,582 & +1729 & 6.3783 & 6.2669 & +0.1114 & 15,521 \\
\hline Hayes et al. [46] & & 47,311 & 45,582 & +1729 & 7.6093 & 7.4988 & +0.1105 & 15,647 \\
\hline
\end{tabular}

Treatment effects refer to clinical model inputs informed by the DEVOTE basal-bolus subgroup for the degludec and glargine U100 treatment arms (Table 1). No differences (switch to glargine U100) refers to the removal of all treatment effects and the basal insulin price difference. Please refer to Online resource 7 for alternative costs and disutilities

$C V$ cardiovascular, dominant improved quality of life at lower or similar cost, GBP pounds sterling, Glargine U100 glargine $100 \mathrm{units} / \mathrm{mL}, H R$ hazard ratio, ICER incremental cost-effectiveness ratio, MACE major adverse cardiovascular events, $M I$ myocardial infarction N/A not applicable, $Q A L E$ quality-adjusted life expectancy, $Q A L Y$ quality-adjusted life year, UKPDS OMI United Kingdom Prospective Diabetes Study Outcomes Model 1, UKPDS OM2 United Kingdom Prospective Diabetes Study Outcomes Model 2

${ }^{a}$ Reported for degludec-glargine U100

${ }^{\mathrm{b}}$ Reported for degludec/glargine U100

${ }^{\mathrm{c}}$ Refers to each individual component of the composite first MACE endpoint (MI, stroke and CV death) in conjunction

${ }^{\mathrm{d}}$ Refers to event rates observed in the glargine U100 arm and estimated in the degludec arm for the DEVOTE basal-bolus subgroup

${ }^{\mathrm{e}}$ Refers to the application of hazard ratios for degludec versus glargine U100 from regression analyses to event rates from UKPDS OM2 projections (these are consistent across treatment arms in the base case analysis)

${ }^{\mathrm{f}}$ Costs inflated to 2017 GBP using the hospital and community health services index from the Personal Social Services Research Unit [27]

${ }^{\mathrm{g}}$ Annualized disutility of -0.0118

As diabetes is a chronic and progressive disease, costeffectiveness analyses (CEAs) of diabetes interventions have traditionally been performed by estimating longterm costs and effectiveness outcomes as a function of differences in glycemic control. However, over at least the last decade, most trials in diabetes of glucose-lowering therapies (especially of insulins) have employed treatto-target protocols, which tend to result in similar $\mathrm{HbA}_{1 \mathrm{c}}$ levels being achieved across comparators. Over the last 5-10 years, this has in turn led to a substantial increase in short-term CEAs based on differences in hypoglycemia rates and dosing, under the assumption that there would be no differences in diabetic morbidity or mortality rates in patients treated to the same $\mathrm{HbA}_{1 \mathrm{c}}$ target. This approach is therefore consistent with the NICE recommendation that CEAs over shorter time horizons could be justified if there is no differential mortality effect between comparators, and if differences between costs and effectiveness outcomes relate to a relatively short period [28]. The findings of several recent CVOTs, in which significant differences in the primary endpoints were reported despite the use of treat-to-target protocols [30], raises important methodological questions about the health-economic assessment of diabetes interventions. For instance, in the DEVOTE basal-bolus subgroup, there was a significantly lower risk of MACE with degludec versus glargine U100 at glycemic parity [19]. This finding highlights the potential for differential mortality effects between treatment comparators and differential clinical outcomes (and associated costs) at equivalent levels of glycemic control, and such differences might persist for longer than the 1- to 2-year time horizons employed in most short-term CEAs of diabetes interventions. This can be used as inspiration for future evaluations and, potentially, more nuanced guidance regarding model inputs including, but not limited to, the time horizon, important clinical and effectiveness outcomes, and the persistence of treatment effects.

One key limitation of the present analysis was that it was conducted in the basal-bolus subgroup of DEVOTE; hence, the results cannot necessarily be extrapolated to all patient populations. Additionally, as with all modeling analyses, the result was dependent on the underlying modeling assumptions, and it can be challenging to make predictions over longer timeframes. However, the influence of 
Fig. 1 Results of the probabilistic sensitivity analysis. a Cost-effectiveness scatterplot. b Cost-effectiveness acceptability curve. For a, the majority of points located in the upper right-hand quadrant of the plot indicates higher costs and improved effectiveness for degludec versus glargine U100. $G B P$ pounds sterling, $Q A L Y$ quality-adjusted life year (a)

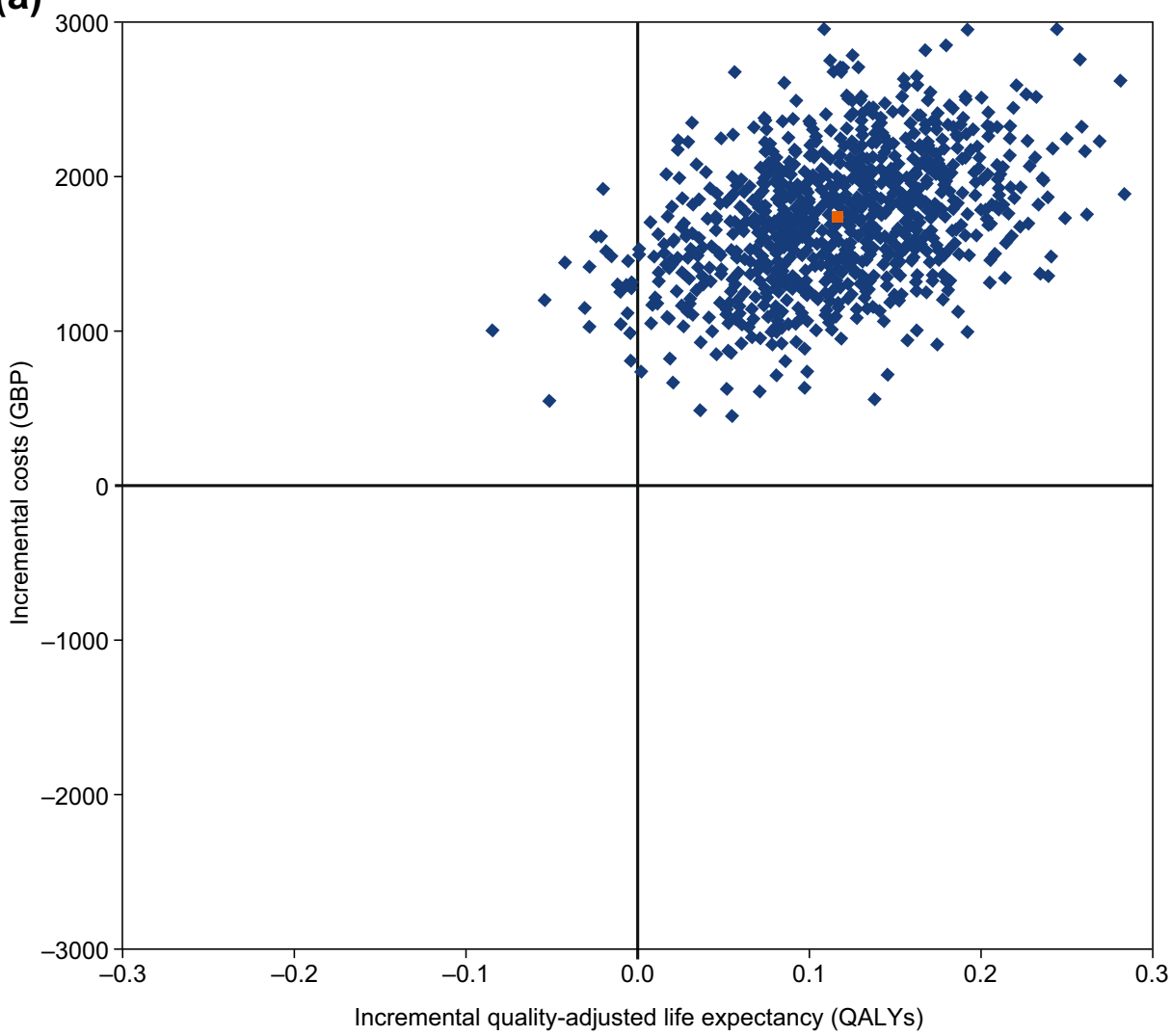

(b)

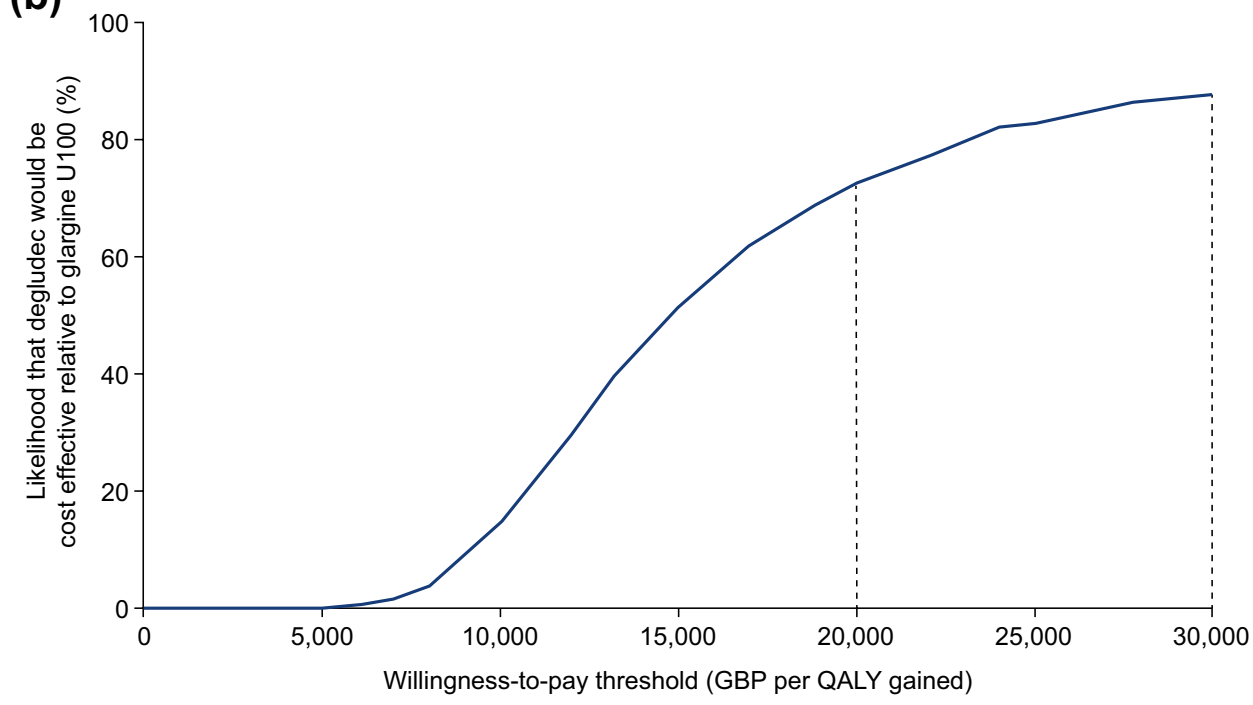

underlying assumptions on the result was investigated in exploratory sensitivity analyses. Furthermore, these analyses are derived from a treat-to-target study in which basal and bolus insulin doses were titrated to achieve target fasting [4-5 mmol/mol (71-90 $\mathrm{mg} / \mathrm{dL})]$ and pre-prandial [4-7 mmol/mol (71-126 mg/dL)] plasma glucose levels. Therefore, the results may not be as relevant to the general population where less stringent targets are applied.
Strengths of this modeling analysis include the highly conservative assumptions in the base case analysis and the estimation of long-term diabetes-related complications using the UKPDS OM2 risk equations, which were derived from up to 89,760 patient-years of data with a median of 17.6 years of follow-up per patient [24]. Furthermore, our results extend the findings of previous comparative analysis for degludec versus glargine U100 that have evaluated 
cost effectiveness over a short-term ( 1 or 2 years) time horizon to provide information on costs and effects based on CV outcomes, severe hypoglycemia and insulin dosing from a patient-lifetime perspective.

In conclusion, our analysis demonstrates that over patient lifetimes, treatment with degludec versus glargine U100 would represent an efficient use of NHS resources in patients with T2D at high CV risk. CVOTs such as DEVOTE provide valuable information and have the potential to transform CEAs of diabetes interventions.

Acknowledgements The authors acknowledge the contribution of Lars Lynne Hansen to the data analysis. Medical writing support was provided by Anna Campbell, Ph.D., and editorial assistance provided by Richard McDonald, of Watermeadow Medical, an Ashfield company, part of UDG Healthcare plc, funded by Novo Nordisk.

\section{Compliance with Ethical Standards}

This article does not contain any new studies with human participants performed by any of the authors.

Data availability The datasets generated during and/or analyzed during the current study are available from the corresponding author on reasonable request.

Funding/support Sponsorship for the DEVOTE clinical trial, this study and article processing charges were funded by Novo Nordisk A/S.

Author contributions RFP and WV contributed to the model design. RFP programmed the model, identified appropriate model parameters from the literature, and ran the analyses. WV reviewed the final model and analyses. All authors reviewed the manuscript, contributed to the interpretation of results, revised the manuscript critically for intellectual content and approved the final version to be published. All authors agree to be accountable for the parts of the work he or she has done and confirm they fulfil the ICMJE authorship criteria.

Financial disclosure RFP was at the time of the study and WV is a full-time employee of Ossian Health Economics and Communications $\mathrm{GmbH}$, which received consultancy fees from Novo Nordisk to construct the model and conduct the analyses. EAM reports research support from Abbott Vascular, Boston Scientific, Cardiovascular Systems, Inc., Daiichi Sankyo and Medtronic. JB reports grant and consultation fees to the University of North Carolina (UNC) under contract and travel/meals/lodging for contracted activities from Novo Nordisk during the conduct of the study and salary support from the National Institutes of Health (UL1TR002489); fees for consultation to UNC under contract and travel/meals/lodging for contracted activities from Adocia, AstraZeneca, Dexcom, Elcelyx Therapeutics, Eli Lilly, Intarcia Therapeutics, Lexicon, MannKind, Metavention, NovaTarg, Novo Nordisk, Sanofi, Senseonics, and vTv Therapeutics; grants from AstraZeneca, Boehringer Ingelheim, Johnson \& Johnson, Lexicon, Novo Nordisk, Sanofi, Theracos, and vTv Therapeutics; stock options in Mellitus Health, PhaseBio and Stability Health outside the submitted work. He is a consultant to Neurimmune AG. AA, DT, JG and $\mathrm{NH}$ are all employees of Novo Nordisk, and AA, DT and JG also hold shares/stocks in Novo Nordisk. SM has received personal fees from Abbott Vascular, Novo Nordisk, Boston Scientific Asahi, BoehringerIngelheim and Bristol-Myers Squibb; and research support from Novo Nordisk.
Open Access This article is distributed under the terms of the Creative Commons Attribution-NonCommercial 4.0 International License (http://creativecommons.org/licenses/by-nc/4.0/), which permits any noncommercial use, distribution, and reproduction in any medium, provided you give appropriate credit to the original author(s) and the source, provide a link to the Creative Commons license, and indicate if changes were made.

\section{References}

1. International Diabetes Federation. IDF Diabetes Atlas, 8th edn. 2017. https://diabetesatlas.org/resources/2017-atlas.html. Accessed June 2019.

2. Kanavos P, Van den Aardweg S, Schurer W. Diabetes expenditure, burden of disease and management in 5 EU countries. London: London School of Economics; 2012.

3. Hex N, Bartlett C, Wright D, Taylor M, Varley D. Estimating the current and future costs of type 1 and type 2 diabetes in the UK, including direct health costs and indirect societal and productivity costs. Diabet Med. 2012;29(7):855-62. https://doi.org/10.111 $1 / \mathrm{j} .1464-5491.2012 .03698 . x$.

4. Caro JJ, Briggs AH, Siebert U, Kuntz KM. Modeling good research practices-overview: a report of the ISPOR-SMDM Modeling Good Research Practices Task Force-1. Value Health J Int Soc Pharmacoecon Outcomes Res. 2012;15(6):796-803. https:// doi.org/10.1016/j.jval.2012.06.012.

5. Palmer AJ, Si L, Tew M, Hua X, Willis MS, Asseburg C, et al. Computer modeling of diabetes and its transparency: a report on the eighth mount hood challenge. Value health J Int Soc Pharmacoecon Outcomes Res. 2018;21(6):724-31. https://doi. org/10.1016/j.jval.2018.02.002.

6. Boussageon R, Bejan-Angoulvant T, Saadatian-Elahi M, Lafont $\mathrm{S}$, Bergeonneau C, Kassai B, et al. Effect of intensive glucose lowering treatment on all cause mortality, cardiovascular death, and microvascular events in type 2 diabetes: meta-analysis of randomised controlled trials. BMJ. 2011;343:d4169. https://doi. org/10.1136/bmj.d4169.

7. Sarwar N, Gao P, Seshasai SR, Gobin R, Kaptoge S, Di Angelantonio E, et al. Diabetes mellitus, fasting blood glucose concentration, and risk of vascular disease: a collaborative meta-analysis of 102 prospective studies. Lancet. 2010;375(9733):2215-22. https ://doi.org/10.1016/s0140-6736(10)60484-9.

8. Gregg EW, Gu Q, Cheng YJ, Narayan KM, Cowie CC. Mortality trends in men and women with diabetes, 1971 to 2000 . Ann Intern Med. 2007;147(3):149-55.

9. Schnell O, Ryden L, Standl E, Ceriello A. Updates on cardiovascular outcome trials in diabetes. Cardiovasc Diabetol. 2017;16(1):128. https://doi.org/10.1186/s12933-017-0610-y.

10. Schnell O, Ryden L, Standl E, Ceriello A. Current perspectives on cardiovascular outcome trials in diabetes. Cardiovasc Diabetol. 2016;15(1):139. https://doi.org/10.1186/s12933-016-0456-8.

11. Marso SP, McGuire DK, Zinman B, Poulter NR, Emerson SS, Pieber TR, et al. Efficacy and safety of degludec versus glargine in type 2 diabetes. N Engl J Med. 2017;377(8):723-32. https:// doi.org/10.1056/NEJMoa1615692.

12. Ericsson A, Pollock RF, Hunt B, Valentine WJ. Evaluation of the cost-utility of insulin degludec vs insulin glargine in Sweden. J Med Econ. 2013;16(12):1442-52. https://doi.org/10.3111/13696 998.2013.852099.

13. Evans M, Wolden M, Gundgaard J, Chubb B, Christensen T. Costeffectiveness of insulin degludec compared with insulin glargine for patients with type 2 diabetes treated with basal insulin-from 
the UK health care cost perspective. Diabetes Obes Metab. 2014;16(4):366-75. https://doi.org/10.1111/dom.12250.

14. Evans M, Wolden M, Gundgaard J, Chubb B, Christensen T. Cost-effectiveness of insulin degludec compared with insulin glargine in a basal-bolus regimen in patients with type 1 diabetes mellitus in the UK. J Med Econ. 2015;18(1):56-68. https://doi. org/10.3111/13696998.2014.971160.

15. Evans M, Chubb B, Gundgaard J. Cost-effectiveness of insulin degludec versus insulin glargine in adults with type 1 and type 2 diabetes mellitus. Diabetes Ther. 2017;8(2):275-91. https://doi. org/10.1007/s13300-017-0236-9.

16. Pollock RF, Tikkanen CK. A short-term cost-utility analysis of insulin degludec versus insulin glargine U100 in patients with type 1 or type 2 diabetes in Denmark. J Med Econ. 2017;20(3):213-20. https://doi.org/10.1080/13696998.2016.1245663.

17. Mezquita-Raya P, Darba J, Ascanio M, Ramirez de Arellano A. Cost-effectiveness analysis of insulin degludec compared with insulin glargine $\mathrm{u} 100$ for the management of type 1 and type 2 diabetes mellitus - from the Spanish National Health System perspective. Expert Rev Pharmacoecon Outcomes Res. 2017;17(6):58795. https://doi.org/10.1080/14737167.2017.1345628.

18. Lalic N, Russel-Szymczyk M, Culic M, Tikkanen CK, Chubb B. Cost-effectiveness of insulin degludec versus insulin glargine U100 in patients with type 1 and type 2 diabetes mellitus in serbia. Diabetes Ther Res Treat Educ Diabetes Relat Disord. 2018;9(3):1201-16. https://doi.org/10.1007/s13300-018-0426-0.

19. Pollock RF, Valentine WJ, Marso SP, Gundgaard J, Hallen N, Hansen LL, et al. DEVOTE 5: evaluating the short-term costutility of insulin degludec versus insulin glargine U100 in basalbolus regimens for type 2 diabetes in the UK. Diabetes Ther. 2018;9(3):1217-32. https://doi.org/10.1007/s13300-018-0430-4.

20. Zoungas S, Woodward M, Li Q, Cooper ME, Hamet P, Harrap $\mathrm{S}$, et al. Impact of age, age at diagnosis and duration of diabetes on the risk of macrovascular and microvascular complications and death in type 2 diabetes. Diabetologia. 2014;57(12):2465-74. https://doi.org/10.1007/s00125-014-3369-7.

21. Elliott L, Fidler C, Ditchfield A, Stissing T. Hypoglycemia event rates: a comparison between real-world data and randomized controlled trial populations in insulin-treated diabetes. Diabetes Ther. 2016;7(1):45-60. https://doi.org/10.1007/s13300-016-0157-z.

22. Marso SP, McGuire DK, Zinman B, Poulter NR, Emerson SS, Pieber TR, et al. Design of DEVOTE (trial comparing cardiovascular safety of insulin degludec vs insulin glargine in patients with type 2 diabetes at high risk of cardiovascular events) - DEVOTE 1. Am Heart J. 2016;179:175-83. https://doi.org/10.1016/j. ahj.2016.06.004.

23. Seaquist ER, Anderson J, Childs B, Cryer P, Dagogo-Jack S, Fish L, et al. Hypoglycemia and diabetes: a report of a workgroup of the american diabetes association and the endocrine society. Diabetes Care. 2013;36(5):1384-95. https://doi.org/10.2337/ dc12-2480.

24. Hayes AJ, Leal J, Gray AM, Holman RR, Clarke PM. UKPDS outcomes model 2: a new version of a model to simulate lifetime health outcomes of patients with type 2 diabetes mellitus using data from the 30 year United Kingdom Prospective Diabetes Study: UKPDS 82. Diabetologia. 2013;56(9):1925-33. https://doi. org/10.1007/s00125-013-2940-y.

25. Clarke PM, Gray AM, Briggs A, Farmer AJ, Fenn P, Stevens RJ, et al. A model to estimate the lifetime health outcomes of patients with type 2 diabetes: the United Kingdom Prospective Diabetes Study (UKPDS) Outcomes Model (UKPDS no. 68). Diabetologia. 2004;47(10):1747-59. https://doi.org/10.1007/s0012 5-004-1527-z.

26. Clarke PM, Simon J, Cull CA, Holman RR. Assessing the impact of visual acuity on quality of life in individuals with type 2 diabetes using the short form-36. Diabetes Care. 2006;29(7):1506-11. https://doi.org/10.2337/dc05-2150.

27. Personal Social Services Research Unit. The hospital and community health services index. 2017. https://www.pssru.ac.uk/pub/ uc/uc2017/sources-of-information.pdf. Accessed June 2018.

28. National Institute for Health and Care Excellence. NICE Process and Methods Guides. Guide to the Methods of Technology Appraisal 2013. 2013. https://www.nice.org.uk/process/pmg9/ chapter/the-reference-case. Accessed Nov 2017.

29. National Institute for Health and Care Excellence. Process and Methods [PMG20]. Developing NICE guidelines: the manual. 2014. https://www.nice.org.uk/process/pmg20/chapter/incorporat ing-economic-evaluation. Accessed Sept 2018.

30. Cefalu WT, Kaul S, Gerstein HC, Holman RR, Zinman B, Skyler JS, et al. Cardiovascular outcomes trials in type 2 diabetes: where do we go from here? Reflections from a diabetes care editors' expert forum. Diabetes Care. 2018;41(1):14-31. https://doi. org/10.2337/dci17-0057.

31. MIMS UK. Monthly index of medical specialities (MIMS). 2018. https://www.mims.co.uk/. Accessed June 2018.

32. Alva ML, Gray A, Mihaylova B, Leal J, Holman RR. The impact of diabetes-related complications on healthcare costs: new results from the UKPDS (UKPDS 84). Diabet Med. 2015;32(4):459-66. https://doi.org/10.1111/dme.12647.

33. Improvement NEaN. National tariff values 2017/18. 2017/18. https://improvement.nhs.uk/resources/national-tariff-1719/. Accessed June 2018.

34. UK Renal Registry. 19th Annual Report of the Renal Association. 2016. https://www.renalreg.org/reports/2016-nineteenth-annua 1-report/. Accessed June 2018.

35. Ghatnekar O, Willis M, Persson U. Cost-effectiveness of treating deep diabetic foot ulcers with Promogran in four European countries. J Wound Care. 2002;11(2):70-4. https://doi.org/10.12968/ jowc.2002.11.2.26675.

36. Hammer M, Lammert M, Mejias SM, Kern W, Frier BM. Costs of managing severe hypoglycaemia in three European countries. J Med Econ. 2009;12(4):281-90. https://doi.org/10.3111/13696 990903336597.

37. Clarke P, Gray A, Holman R. Estimating utility values for health states of type 2 diabetic patients using the EQ-5D (UKPDS 62). Med Decis Mak Int J Soc Med Decis Mak. 2002;22(4):340-9. https://doi.org/10.1177/0272989x0202200412.

38. Wasserfallen JB, Halabi G, Saudan P, Perneger T, Feldman HI, Martin PY, et al. Quality of life on chronic dialysis: comparison between haemodialysis and peritoneal dialysis. Nephrol Dial Transplant. 2004;19(6):1594-9. https://doi.org/10.1093/ndt/gfh17 5 .

39. Bagust A, Beale S. Modelling EuroQol health-related utility values for diabetic complications from CODE-2 data. Health Econ. 2005;14(3):217-30. https://doi.org/10.1002/hec.910.

40. Evans M, Khunti K, Mamdani M, Galbo-Jorgensen CB, Gundgaard J, Bogelund M, et al. Health-related quality of life associated with daytime and nocturnal hypoglycaemic events: a time trade-off survey in five countries. Health Qual Life Outcomes. 2013;11:90. https://doi.org/10.1186/1477-7525-11-90.

41. Waugh N, Cummins E, Royle P, Clar C, Marien M, Richter B, et al. Newer agents for blood glucose control in type 2 diabetes: systematic review and economic evaluation. Health Technol assessment (Winchester, England). 2010;14(36):1-248. https:// doi.org/10.3310/hta14360.

42. Currie CJ, Morgan CL, Poole CD, Sharplin P, Lammert M, McEwan P. Multivariate models of health-related utility and the fear of hypoglycaemia in people with diabetes. Curr Med Res Opin. 2006;22(8):1523-34. https://doi.org/10.1185/030079906x11575 7. 
43. Hunt B, Ye Q, Valentine WJ, Ashley D. Evaluating the long-term cost-effectiveness of daily administered GLP-1 receptor agonists for the treatment of type 2 diabetes in the United Kingdom. Diabetes Ther. 2017;8(1):129-47. https://doi.org/10.1007/s1330 0-016-0219-2.

44. Sullivan PW, Ghushchyan VH. EQ-5D scores for diabetesrelated comorbidities. Value Health J Int Soc Pharmacoecon Outcomes Res. 2016;19(8):1002-8. https://doi.org/10.1016/j. jval.2016.05.018.

45. Palmer AJ, Roze S, Valentine WJ, Minshall ME, Foos V, Lurati FM, et al. The CORE diabetes model: projecting long-term clinical outcomes, costs and cost-effectiveness of interventions in diabetes mellitus (types 1 and 2) to support clinical and reimbursement decision-making. Curr Med Res Opin. 2004;20(Suppl 1):S5-26. https://doi.org/10.1185/030079904x1980.

46. Hayes A, Arima H, Woodward M, Chalmers J, Poulter N, Hamet $\mathrm{P}$, et al. Changes in quality of life associated with complications of diabetes: results from the ADVANCE study. Value Health J Int Soc Pharmacoecon Outcomes Res. 2016;19(1):36-41. https://doi. org/10.1016/j.jval.2015.10.010. 